Research Article

\title{
Modelling and Simulation on Penetration into Stone Concrete
}

\author{
He Huang $\mathbb{D}^{\text {, Duo Zhang }} \mathbb{D}^{\mathbb{D}}$, and Lirong Cheng \\ College of Liberal Arts and Sciences, National University of Defense Technology, Changsha 410073, China \\ Correspondence should be addressed to Duo Zhang; zhangduo@nudt.edu.cn
}

Received 3 June 2021; Accepted 18 July 2021; Published 2 August 2021

Academic Editor: Zhengyang Song

Copyright (c) 2021 He Huang et al. This is an open access article distributed under the Creative Commons Attribution License, which permits unrestricted use, distribution, and reproduction in any medium, provided the original work is properly cited.

Penetration into stone concrete is an important research area of concrete penetration, and related experiments and simulation tests have been carried out. However, complete theories have not been formed yet. This paper develops a differential facet resistance model for penetration into stone concrete target. Firstly, the plastic damage model is used to analyze the penetration of concrete target, and the reliability of the numerical model is verified by comparing with the classical experimental results. Besides, the numerical model of stone concrete is established based on 3D Voronoi diagram according to the random characteristics of the shape and spatial distribution of stones in concrete. Then, simulation tests are carried out with the validated numerical model, a differential facet resistance model suitable for the penetration of stone concrete target is then proposed referring to the resistance formula of Forrestal and Rosenberg. At last, a method for fast calculation of penetration into stone concrete is introduced.

\section{Introduction}

As a common building material, concrete is widely used in various military facilities, such as bunkers, plane holes, and missile silos. The research of concrete penetration has a long history, in which the resistance model of projectile is an important content. The most widely used theory currently is the dynamic cavity expansion theory and its application range has been extended to rocks and soils other than metals and concrete with the diversification of target media [1]. The dynamic cavity expansion theory holds that the resistance of the projectile consists of two terms including quasi-static resistance term (the strength term) and dynamic resistance term (the inertial term). The intensity term is determined by the strength of the target and the inertial term depends on velocity of the projectile and density of the target. The strength term is dominant at lower speed, while the inertia term is dominant at higher speed. As the velocity of the projectile decreases gradually, the strength term gradually occupies the dominant position. Based on the cavity expansion theory, Forrestal et al. [2] proposed a semianalytical expression of the total axial resistance of ogive nosed projectile penetrating semi-infinite thick concrete and differentiated the forces in the pit area and the tunnel area. Li and Chen [3] extended it to any warhead shape, and the empirical relationship of dimensionless constant reflecting the impact characteristics of concrete was given. Rosenberg and Dekel [4] believed that resistance of penetrating concrete only included constant term under rigid projectile hypothesis. Wang et al. [5] pointed out that penetration resistance of rock-like media was expected to be expressed as a function of velocity at lower velocity and gave analytical expressions of differential facet stresses in different velocity intervals.

The addition of rebars, stones, composite fiber, and other materials is of great benefit to enhance the protective performance of concrete. Among them, stone concrete is formed by embedding a large number of stones in the process of pouring concrete, and its buried stone rate (the volume fraction of stones) can reach up to $25 \%$. Stone concrete has been widely used due to the availability and cheapness of stones. When the size of stones is close to or larger than the diameter of projectile, the projectile penetrating stone concrete is easy to be affected by stones and cause instability, deviation, and other phenomena, resulting in the decrease of vertical penetration depth. Wang et al. [6] proposed a random aggregate model for concrete, which regarded concrete as a three-phase heterogeneous composite material composed of aggregate, cement mortar, and bonding band between them. Wang et al. [7] used numerical 
simulation to analyze the effects of coarse aggregate types and volume fraction of coarse aggregate on the penetration resistance of the target plate and extended the Forrestal resistance model. Deng et al. [8] quantitatively analyzed the influence of concrete mesofactors on ballistic deflection in the process of normal penetration with rigid projectile based on the three-dimensional mesonumerical model of concrete. The establishment and research of the concrete mesomodel have certain enlightening effect on the study of penetration of stone concrete. Size of stones in stone concrete is much bigger than the size of aggregate in concrete, due to which concrete is regarded as uniform medium when analyzing penetration into stone concrete. With the random distribution of types, shapes, and positions of stones in stone concrete, experimental research and numerical simulation methods are usually adopted. Langheim et al. [9] carried out a series of experiments on the antipenetration performance of stone concrete, and the results show that stone concrete has better antipenetration performance than ordinary concrete. Guo et al. [10] established a characterization model for the penetration resistance of spherical particles based on the theory of dynamic cavity expansion and analyzed the influence of the strength, position, and size of particles on the penetration resistance. However, there is still lack of a relatively mature and complete theoretical model at present. Exploring the resistance characteristics of projectile in the process of penetrating stone concrete can not only provide reference for further improving the protective performance of the target but also have certain reference significance for optimizing the armor-piercing performance of weapons penetrating stone concrete.

\section{Establishment and Verification of Finite Element Model}

2.1. Establish and Verify the Numerical Model of Concrete. Due to the random spatial distribution of the shape, size, and position of stones in concrete, it is hard to compare simulation test for penetration of stone concrete with corresponding penetration experiment. Considering that the volume fraction of stones approaches zero, the resistance of the projectile is close to that of penetrating concrete, and the classic penetration experiments of concrete are therefore used as the control. Hanchak et al. [11] carried out experiments on penetration of reinforced concrete. As the reinforcement ratio of reinforced concrete is only $0.1 \%$ and there is no contact between the projectile and the rebar, it meets the requirements of the control test. In the numerical simulation, the unit system is selected as $\mathrm{g}-\mathrm{cm}-\mu \mathrm{s}$. By referring to the experiment of Hanchak, the shape of the projectile is set as ogive nosed, the length of the projectile $L=14.37 \mathrm{~cm}$, the diameter of the projectile body $D=2.54 \mathrm{~cm}$, and the curvature radius of the warhead $S=7.62 \mathrm{~cm}$, as shown in Figure 1. The size of the concrete is set as $61 \mathrm{~cm} \times 61 \mathrm{~cm} \times 17.8 \mathrm{~cm}$. In order to improve the calculation efficiency and keep consistent with the subsequent establishment of stone concrete, the $1 / 2$ model is adopted here.

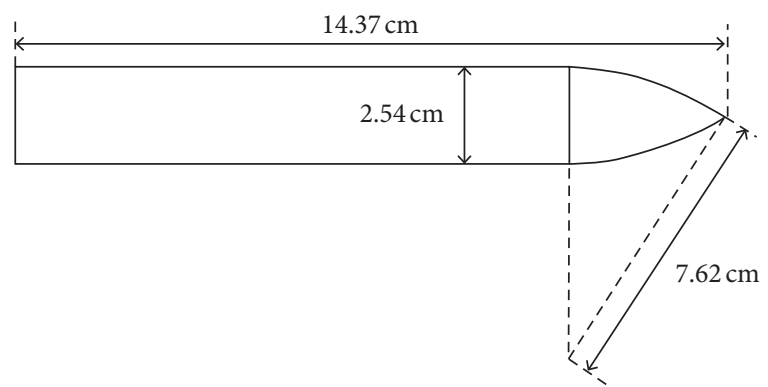

FIGURE 1: The geometry of projectile.

When the velocity is lower than $1000 \mathrm{~m} / \mathrm{s}$, the deformation and mass loss of the projectile in the process of penetration can be ignored, so *MAT_RIGID model is chosen for the projectile. The K\&C (*MAT_CONCRETE_DAMAGE_REL3) material model [12] is selected for concrete. In this model, three shear failure planes (initial yield plane, ultimate strength plane, and residual failure plane) are adopted, and the strain rate effect, damage effect, strain strengthening, and softening effect are taken into consideration. It must be used in conjunction with $*$ MAT_ADD_EROSION, otherwise it will result in severe distortion of grid and affect the experimental results. Solid164 unit is used for concrete. The density of concrete $\rho_{c}=2440 \mathrm{~kg} / \mathrm{m}^{3}$, the unconfined compressive strength $Y=48 \mathrm{MPa}$, and the uniaxial tensile strength $\sigma_{c}=4 \mathrm{MPa}$. Erosion algorithm is selected for the contact between the projectile and concrete, and corresponding constraint conditions are set for the boundary of concrete. In the penetration path of projectile, the mesh of concrete is refined, as shown in Figure 2.

In simulation tests, the material invalidation model will delete the elements after failure. However, failed elements will not be deleted in the actual situation but still have a certain shear strength under the confining pressure of surrounding elements. Through a lot of simulation tests, it is found that the numerical solution of residual velocity decreases obviously after tessellated mesh. When the mesh size is kept invariable, with the increase of the failure value of the principal strain in a certain range, the numerical solution of the residual velocity also shows a significant decrease in the direction towards the experimental results. This does not mean that we can select a large failure value or reduce the size of mesh indefinitely for higher accuracy arbitrarily. Excessive failure value for principal strain will result in overlarge force, and inordinate mesh refinement will lead to exponential growth in calculation time. For this numerical model, we set the principal strain failure value to 0.2. The experiment of Hanchak et al. did not obtain the real-time force of the projectile. Our purpose is to study the resistance of the projectile in the process of penetrating the stone concrete, and the effect of the resistance action could be represented by the residual velocity. Therefore, the comparison between the simulation tests and the experiments could be carried out by comparing the residual velocity. Table 1 gives the residual velocities corresponding to different penetration velocities in simulation and experiment. 


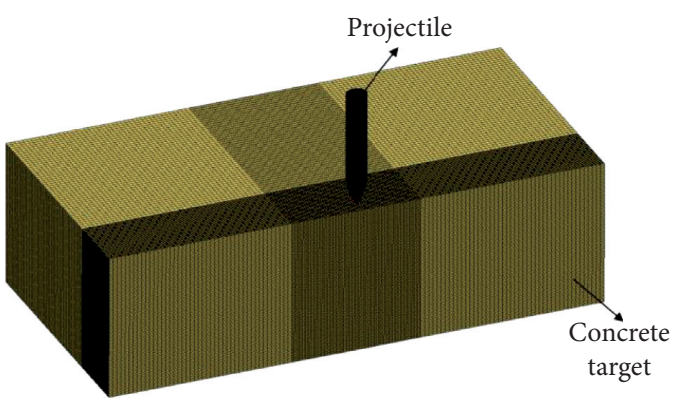

Figure 2: The finite element model of concrete penetration.

TABLE 1: Comparisons of residual velocity between experiment and simulation.

\begin{tabular}{lcc}
\hline Incident velocity $(\mathrm{m} / \mathrm{s})$ & \multicolumn{2}{c}{ Residual velocity $(\mathrm{m} / \mathrm{s})$} \\
& Experiment & Simulation \\
\hline 360 & 67 & 176 \\
381 & 136 & 197 \\
434 & 214 & 262 \\
606 & 449 & 453 \\
749 & 615 & 598 \\
1058 & 947 & 927 \\
\hline
\end{tabular}

The simulation results deviate greatly from the experimental results at the velocity of $360 \mathrm{~m} / \mathrm{s}, 381 \mathrm{~m} / \mathrm{s}$, and $434 \mathrm{~m} /$ $\mathrm{s}$, and the deviation ratio is less than $3 \%$ in the other three conditions, which is in good agreement with the experimental results. It is reasonable to believe that the numerical model can achieve a good simulation of the response characteristics of concrete at the velocity of $600 \sim 1000 \mathrm{~m} / \mathrm{s}$. In the subsequent simulation, the unit type and material parameters are all selected and refer to verified model parameters, and the penetration resistance model suitable for velocity of $600 \sim 1000 \mathrm{~m} / \mathrm{s}$ is mainly studied.

\subsection{Establish the Numerical Model of Stone Concrete.} Taking into account the differences in the material properties of stones and concrete, the space and shape distribution of stones has an obvious influence on the material properties of stone concrete. In the traditional numerical model of stone concrete, spherical, hexahedral, and ellipsoid are usually used to simulate stones. The random distribution of stone position in space can be realized through algorithm, but the shape of stones is obviously different from the actual situation. As a basic data structure, Voronoi diagram is suitable for simulating natural structures such as rocks and animal skin textures. The random distribution of shape and space of stones in concrete can be realized well by threedimensional Voronoi diagram, which can be used as a method to establish random aggregate model of stone concrete. A three-dimensional Voronoi diagram is composed of a set of continuous polyhedrons formed by the vertical bisecting plane of line segment connected by all two adjacent points in space. Assuming there are $\mathrm{N}$ discrete points in the space, it can be divided into $N$ continuous polyhedrons according to the principle of maximum proximity, as shown in Figure 3.
Assume that the Euclid Distance of points $x\left(x_{1}, x_{2}, x_{3}\right)$ and $y\left(y_{1}, y_{2}, y_{3}\right)$ can be expressed as follows:

$$
|x, y|=\sqrt{\left(x_{1}-y_{1}\right)^{2}+\left(x_{2}-y_{2}\right)^{2}+\left(x_{3}-y_{3}\right)^{2}} .
$$

Then, the three-dimensional Voronoi diagram satisfies the following properties:

(1) There is only one discrete point in each polygon region.

(2) Any point $P$ inside each polyhedron can satisfy

$$
\left|p, k_{i}\right|<\left|p, k_{j}\right|, \quad i, j=1,2, \ldots, N, j \neq i,
$$

where $k_{i}$ is the discrete point in the polyhedron and $k_{j}$ is the discrete point in other polyhedrons.

(3) Point $Q$ on the boundary of any two adjacent polyhedrons can satisfy

$$
\left|q, k_{i}\right|=\left|q, k_{j}\right|, \quad i, j=1,2, \ldots, N, j \neq i,
$$

where $k_{i}$ and $k_{j}$ are discrete points in two adjacent polyhedrons, respectively.

Based on the background grid method, the finite element model of three-dimensional Voronoi diagram can be established. Firstly, establish the corresponding spatial region according to the shape of the target, which is divided into basic hexahedral elements with small size. In order to make the stones distribute in space evenly, the spatial region can be divided into cube regions with edge length of $a_{0}$. Discrete points can be generated randomly in each small region; then, three-dimensional Voronoi diagram can be generated based on these discrete points. The size of stones can be adjusted by changing the value of $a_{0}$, which is defined as target scale of stones. After the finite element model of three-dimensional Voronoi diagram is generated in the corresponding region, random extraction is carried out by the Monte Carlo method. With the volume fraction of stones as the constraint condition, polyhedrons are selected to represent the stones as to realize the random distribution of space and shape of stones. Then, the selected polyhedrons are projected into the finite element model and attributes of the elements are assigned according to the position. When all nodes of an element fall into the polyhedron region, the element is assigned attributes of stones, and the rest of the elements are assigned attributes of concrete, as shown in Figure 4 .

2.3. Simulation Tests and Analysis. Granite is used for stones and Solid164 unit is used for elements. The K\&C model is selected as the material model, and main material parameters and maximum principal strain [13] are given in Table 2. In order to verify the rationality of the material parameters briefly, a simulation test is carried out on the penetration velocity of $1000 \mathrm{~m} / \mathrm{s}$ into an infinite-thickness rock target and the penetration depth is $33.44 \mathrm{~cm}$. The penetration depth formula of rock proposed by Bernard and Creighton [14] in 1979 is used as a contrast. When RQD (rock quality 


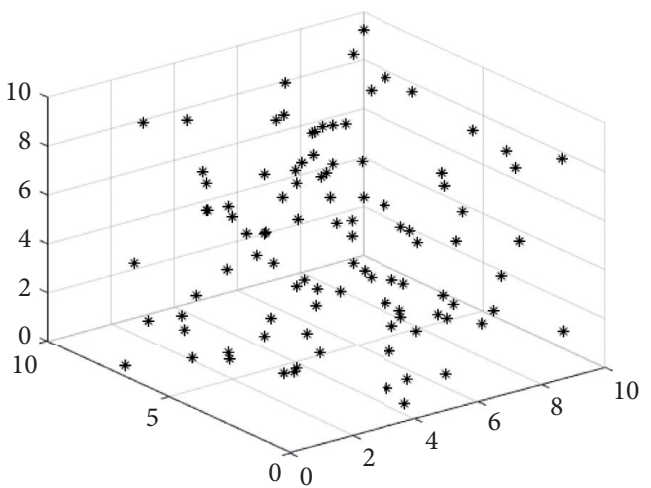

(a)

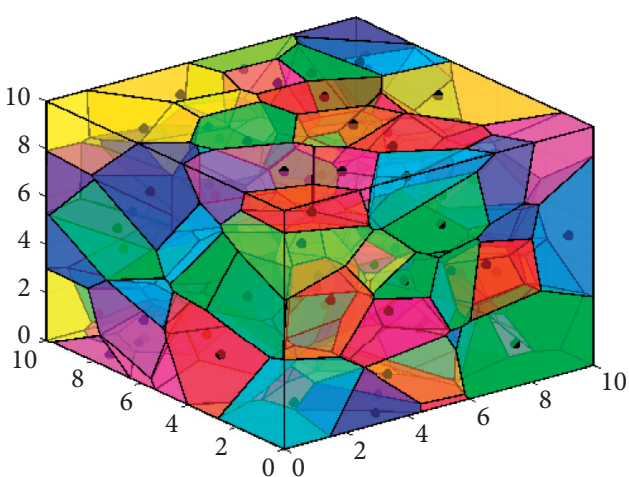

(b)

Figure 3: Voronoi diagram generated by $N$ discrete points. (a) Generation of discrete points. (b) Division of volume.

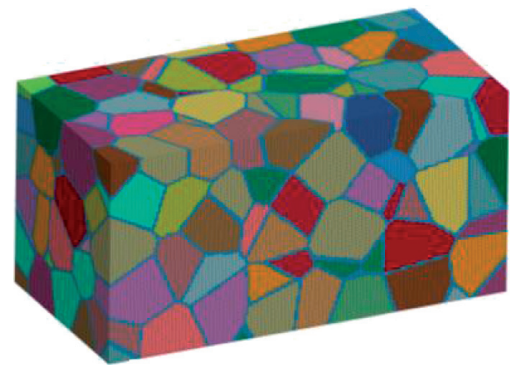

(a)

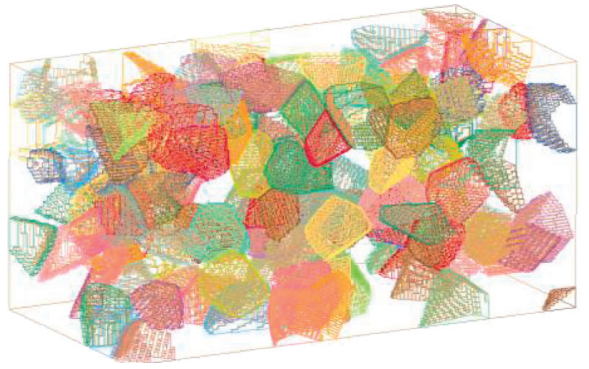

(b)

FIGURE 4: Finite element model of 3D-Voronoi diagram and stone concrete. (a) Finite element model of 3D-Voronoi diagram. (b) Finite element model of stone concrete.

TABLE 2: Material parameters of stone.

\begin{tabular}{lcccc}
\hline$\rho\left(\mathrm{kg} / \mathrm{m}^{3}\right)$ & $\mathrm{PR}$ & $f_{c}(\mathrm{MPa})$ & $R$ size & UCF \\
\hline 2600 & 0.15 & 154 & 0.394 & $1.45 \times 10^{7}$ \\
\hline
\end{tabular}

conductor) is set to $90 \%$, the calculation result of penetration depth is $32.42 \mathrm{~cm}$, which is consistent with the simulation test.

The shape of the projectile is set as ogive nosed, of which length $L=45 \mathrm{~cm}$ and diameter $D=6 \mathrm{~cm}$. Curvature radius of the warhead $S=24 \mathrm{~cm}$. The $1 / 2$ model is adopted for stone concrete, and its size is set as $100 \mathrm{~cm} \times 50 \mathrm{~cm} \times 50 \mathrm{~cm}$. Set a symmetric constraint on the symmetric surface and set a nonreflecting boundary condition for the side. The target scale of stones is $10 \mathrm{~cm}$ and the target volume fraction is set as $25 \%$. In the actual generated model, the volume fraction of stone is $25.07 \%$. The meshing is divided in equal proportion to achieve local refinement of penetration path. The velocity of projectile is set as $1000 \mathrm{~m} / \mathrm{s}$ and simulation tests are carried out on a rigid projectile penetrating a finite-thickness stone concrete target.

Figure 5 presents the simulation results of a projectile penetrating finite-thickness stone concrete at different moments. The projectile acts with three stones in the process of penetration. Compared with the direction of incident velocity, the projectile deflects at a certain angle when it ejects from the target. The figure also shows the distribution of the damage degree of the internal elements of the stone concrete. The damage ranges from 0 to 2 representing the gradual enhancement of the damage degree. Since the strength of stone is higher than that of concrete, the damage of concrete element is more likely to reach 2 . Therefore, the propagation of cracks is affected by the spatial distribution of stones and concrete. The cracks farther away from the projectile will prefer to develop inside the concrete and cracks will spread between the stones first.

The projectile interacts with three stones on the penetration path and the contact force-time curves between the projectile and stones are output, as shown in Figure 6. It can be seen that the peak value of the contact force between stone 1, 2, and 3 and the projectile decreases gradually and stone 1 has the longest force duration with the projectile. It can be assumed that the magnitude of the force is affected by velocity of the projectile, while the duration of the force is affected by both the stone size and velocity of the projectile.

\section{Establishment of Resistance Model for Penetrating into Stone Concrete}

3.1. The Basic Form of Resistance. In the penetration process of concrete and stone, $Z$ is the penetration depth of the projectile and $a$ is the radius of the projectile body. The penetration process is divided into two stages including 


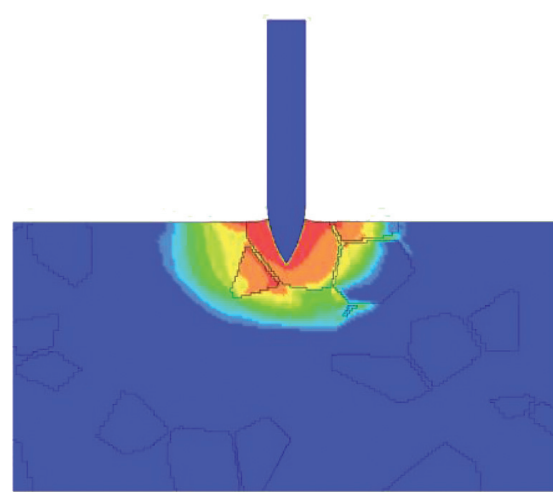

(a)

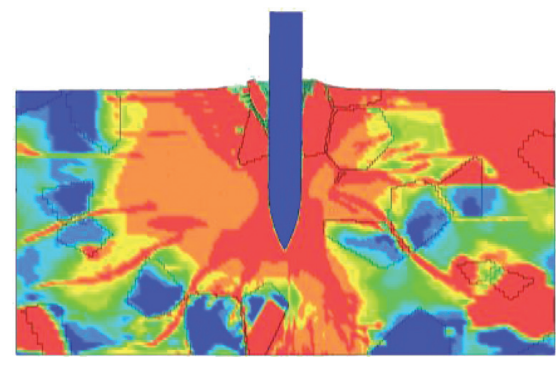

(c)

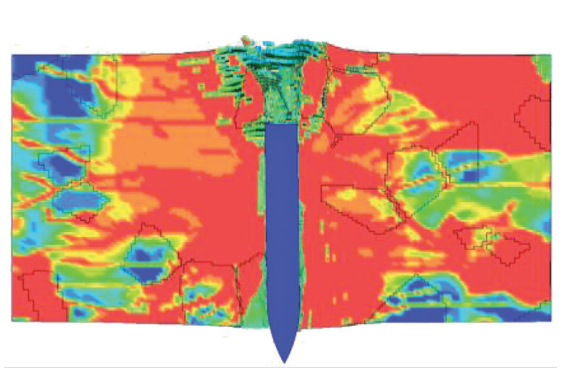

(e)

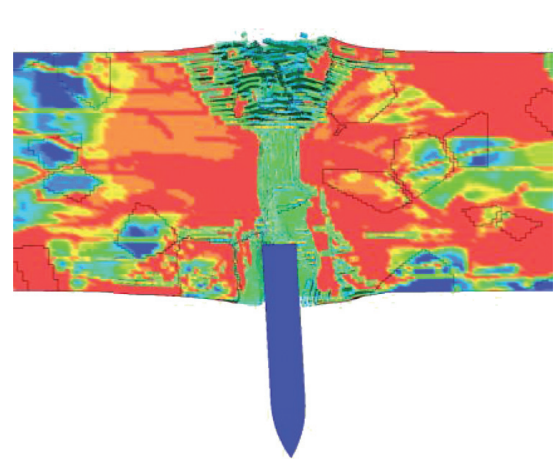

(g)

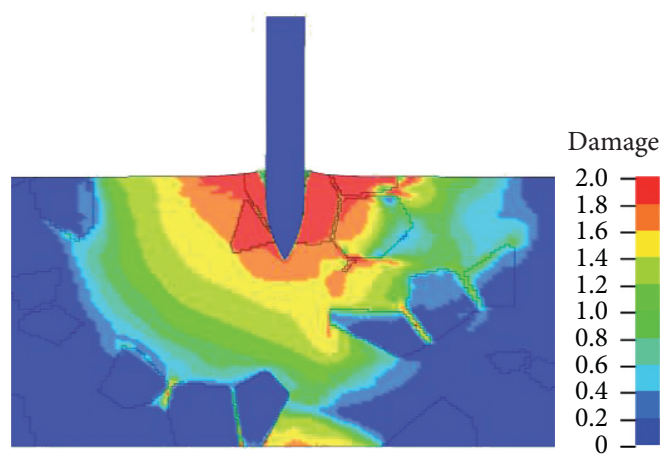

(b)

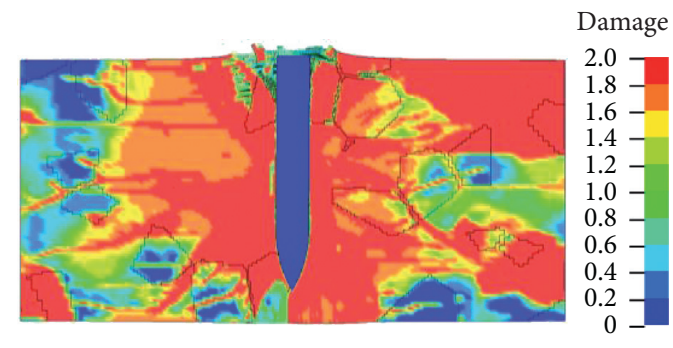

(d)

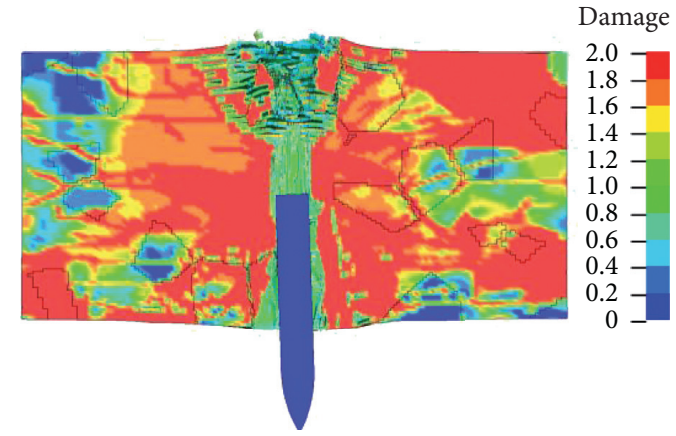

(f)

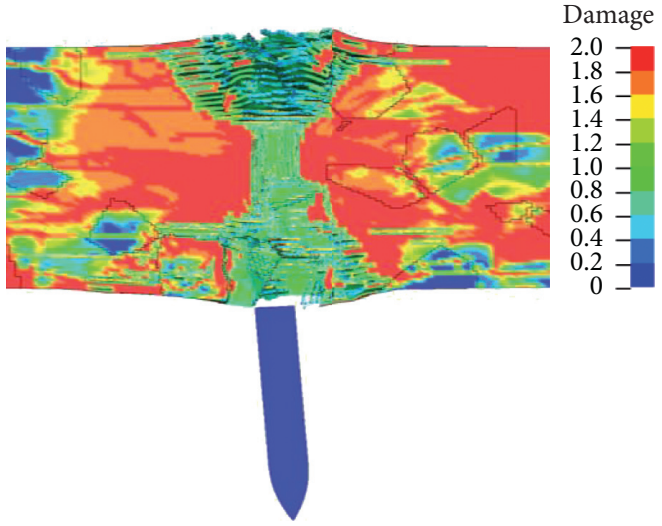

(h)

Figure 5: Simulation results of penetration into finite-thickness stone concrete. (a) $t=100 \mu \mathrm{s}$. (b) $t=200 \mu \mathrm{s}$. (c) $t=300 \mu \mathrm{s}$. (d) $t=400 \mu \mathrm{s}$. (e) $t=500 \mu \mathrm{s}$. (f) $t=600 \mu \mathrm{s}$. (g) $t=700 \mu \mathrm{s}$. (h) $t=800 \mu \mathrm{s}$.

cratering stage when $Z<4 a$ and tunnel stage when $Z>4 a$. The resistance of the projectile increases gradually in the cratering stage and decreases gradually in the tunnel stage.
Under the assumption of rigid projectile and normal impact, Forrestal et al. [2] concluded the resistance of the ogive nosed projectile in the process of penetrating concrete 


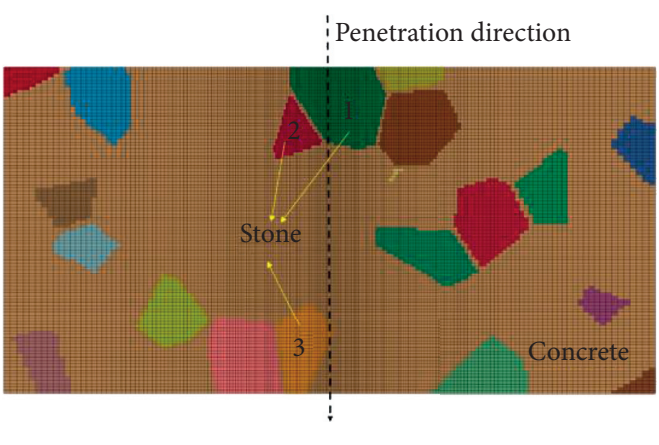

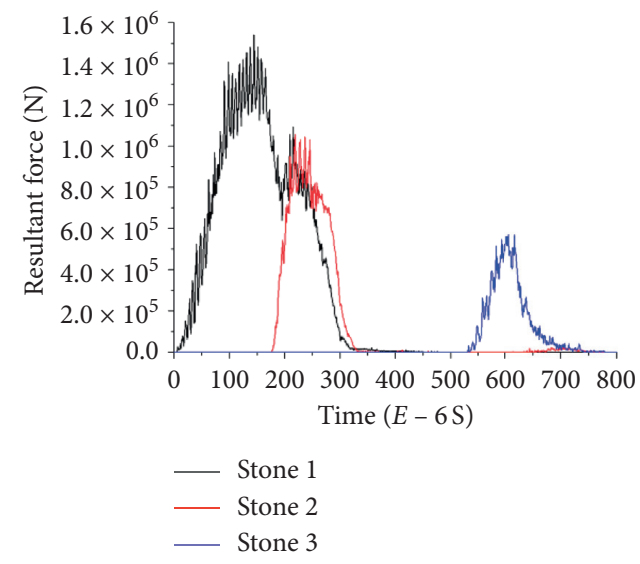

(b)

FIGURE 6: Contact force-time curves of stones collided by the projectile. (a) Stones numbered in the penetration path. (b) Contact force-time curves of stones.

without friction based on the cavity expansion model, which can be expressed as follows:

$$
\begin{aligned}
F & =\pi a^{2}\left(R_{t}+\rho_{0} N v(t)^{2}\right), \\
Z & >4 a, \\
R_{t} & =S f_{c}, \\
N & =\frac{8 \psi-1}{24 \psi^{2}},
\end{aligned}
$$

where $a(\mathrm{~m})$ is the radius of the projectile body, $f_{c}(\mathrm{~Pa})$ is the unconfined compressive strength of concrete, and $R_{t}$ is the static resistance term. Nondimensional constant $S$ is only determined by $f_{c}^{\prime}\left(f_{c}^{\prime}\right.$ takes the unit of $\left.\mathrm{MPa}\right)$, which can be calculated approximately with $S=72 f_{c}^{\prime-0.5}, N$ is the shape factor of the warhead, $\rho_{0}\left(\mathrm{~kg} / \mathrm{m}^{3}\right)$ is the density of the concrete, and $v(t)(\mathrm{m} / \mathrm{s})$ is the axial velocity of projectile at moment $t . \psi$ is caliber radius head, which is the ratio of curvature radius $s$ of the warhead to diameter $d$ of the projectile body.

Rosenberg and Dekel [4] pointed that the penetration resistance under rigid projectile condition only includes constant term of which the expression is as follows:

$$
\begin{aligned}
F & =\pi a^{2} R_{t} \\
& =\pi a^{2}\left(1.1 \ln \frac{E_{t}}{Y_{t}}-\phi\right),
\end{aligned}
$$

where $E_{t}$ is the elastic modulus of the target and $Y_{t}$ is the yield stress of the target. For the ogive nosed projectile, 1.15 is taken for $\phi$.

When the penetration velocity is less than $1000 \mathrm{~m} / \mathrm{s}$, the Rosenberg resistance model is more in line with the actual situation than the Forrestal formula [15]. However, the derivation process of the Forrestal formula is based on the theoretical model of dynamic cavity expansion and has a strict physical basis, while the Rosenberg resistance model is a semiempirical formula based on experimental results.

In the process of penetrating stone concrete, the velocity of projectile deviates from the axis direction due to the action of stones, as shown in Figure 7. At this time, the panel $P$ on the surface of the warhead contacted with stone. $n_{p}$ is the unit vector at the outer normal direction of facet $P . \beta$ is the angle between the outside normal direction and the velocity of facet $P$. It can be considered that there is a force between the facet and the target when $\cos \beta>0$. According to the dynamic cavity expansion theory, the stress on the facet satisfies the following form:

$$
\sigma=R_{t}+B \rho_{0}(v \cos \beta)^{2},
$$

where $R_{t}=A Y$ and $R_{t}$ is related to the strength $Y . \rho_{0}$ is the density of the target, $v$ is the velocity of the surface element, and $A$ and $B$ are nondimensional constants determined by the material of target. Although there are differences in the properties of stones and concrete, the forces on the surface elements in contact with the concrete and stones can be expressed in the same form above.

3.2. Modify the Stress Model of Differential Facet. The resistance of projectile subjected to stones is mainly affected by the velocity of projectile and the size and the strength of stones. The influence of various factors is analyzed as below. Before establishing the stress model of facet, we need to acknowledge the following assumptions:

(1) Rigid projectile hypothesis, which means the projectile does not deform in the process of penetration

(2) Contact between stones and concrete is regarded as ideal bonding, both of which are uniform medium

In the simulation tests, in order to facilitate the analysis of the influence of various factors, stones are represented by spheres. The size of the projectile refers to the Hanchak experiment [11], and the target of $30 \mathrm{~cm} \times 30 \mathrm{~cm} \times 90 \mathrm{~cm}$ is set to simulate the infinite-thickness target. The symmetric 


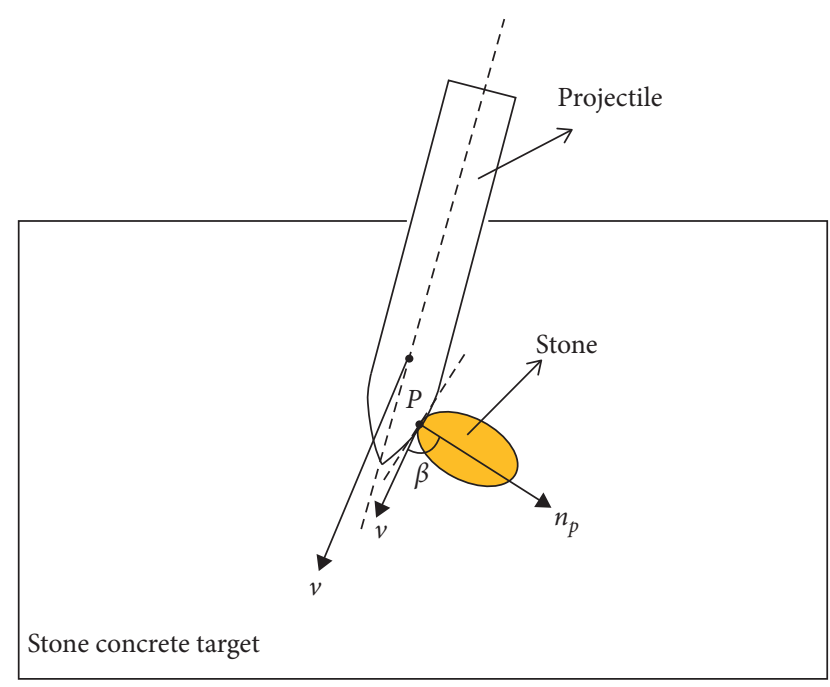

Figure 7: The projectile acts with stone when penetrating into stone concrete.

surface is subjected to symmetric constraints and the nonreflecting boundary is set on the side.

3.2.1. Influence of Stone Size on Stress of Facet. In the process of penetration into stone concrete, the length of stone at the direction of the outside normal direction of the facet is defined as the effective length of stone. In order to analyze the influence of effective length on the stress and avoid the influence of surface effect, the distance between the near end of the stone and the target surface is fixed to $20 \mathrm{~cm}$, in which the velocity of projectile contacting stone is kept the same as far as possible. The ratio of the diameter $D$ of the spherical stone to the diameter $d$ of the projectile body is defined as the relative size $d_{s}$, and the numerical experiments of forward penetration of single stone are carried out with $d_{s}$ equaling to $0.5,1,2,3,4$, and 5 , respectively.

In Figure 8, contact force-time curves of stones of different sizes shows the contact force-time curves between the projectile and the stone of different relative sizes. After smoothing the curves, it is obvious that there is no significant difference in the rising rate of the contact force of stones of different relative sizes under the condition of the same impact velocity. The rising rate is believed to depend on the projectile velocity and warhead shapes. However, the peak value of the contact force shows obvious difference. When the relative size ranges from 0.5 to 2 , the peak value increases gradually. When the relative size ranges from 2 to 5 , the peak value does not change significantly. When the relative size is 0.5 or 1 , not all the facets of the warhead contact with the stone at the time peak value occurs. $N_{s}$ is the number of the facets contacting with the stone on the warhead and $N_{0}$ is the total number of the facets on the projectile. While the relative size is larger than 2 , the ratio of $N_{s}$ to $N_{0}$ is approaching 1; therefore, the peak value of the contact force will tend to be stable. The duration of the contact force has a great relationship with the size of the stone. The larger the size of the stone becomes, the longer the force acts, but it does not satisfy the multiple relationship.

3.2.2. Influence of Stone Strength on Stress of Facet. In order to explore the influence of stone strength on stress of facets, the uniaxial compressive strength of stone is used to represent strength. Normal penetration simulation tests of a single stone with uniaxial compressive strength of 100,120 , 140,160 , and $180 \mathrm{MPa}$ are set. The material parameters of the stone refer to the verified model. The radius $D$ of the stone is set as 2 times of the diameter of the projectile body and the distance between the near end of the stone and the surface of concrete is $20 \mathrm{~cm}$. The penetration velocity of the projectile body is set to $1000 \mathrm{~m} / \mathrm{s}$. The comparison between the resistance peak value of the simulation experiment results and the calculated result of corresponding velocity by the Forrestal formula is shown in Figure 9.

It is obvious that, with the increase of strength of stone, the peak value of contact force with the same penetration velocity increases gradually. For stones of different intensities, the deviation between calculation results of the Forrestal formula and results of simulation tests is within $9 \%$. It can be considered that the Forrestal formula is suitable for solving the stone concrete penetration in a certain range. When the relative size is greater than 2, the resistance of penetrating stone concrete can be calculated approximately by using the Forrestal formula. However, with the increase of strength of stone, deviation between calculation results with the Forrestal formula and results of simulation test tends to become higher and higher, which may be related to the strength of stone.

\subsubsection{Influence of Penetration Velocity on Stress of Facet.} In fact, there is a certain relationship between the static resistance term $R_{t}$ and penetration velocity under the condition of general velocity [15]. The concrete penetration experiments carried out by Xu [16] showed that $R_{t}$ would be different for different penetration velocities. Therefore, it is necessary to consider the effect of velocity on the static resistance term in the process of penetration. The simulation tests of penetrating concrete and stone target are set to explore the relationship between the static resistance term and the projectile velocity. The initial velocity of projectile is set to $1000 \mathrm{~m} / \mathrm{s}$.

Figure 10 shows the contact force between the projectile, and the target increases at the initial stage and then gradually decreases for both concrete and rock targets. It can be analyzed that when the velocity of the projectile gradually closes to 0 , the resistance should also gradually approach 0 . However, neither the Forrestal model nor the Rosenberg resistance model takes it into account that the relationship between the velocity and the static resistance term $R_{t}$ cannot fit the force change in the process of penetration well.

Wang et al. [5] pointed out that the linear elastic internal friction compression model can be used for the dynamic deformation of rock-like media at a low velocity. The penetration resistance of the projectile can be expressed as a 


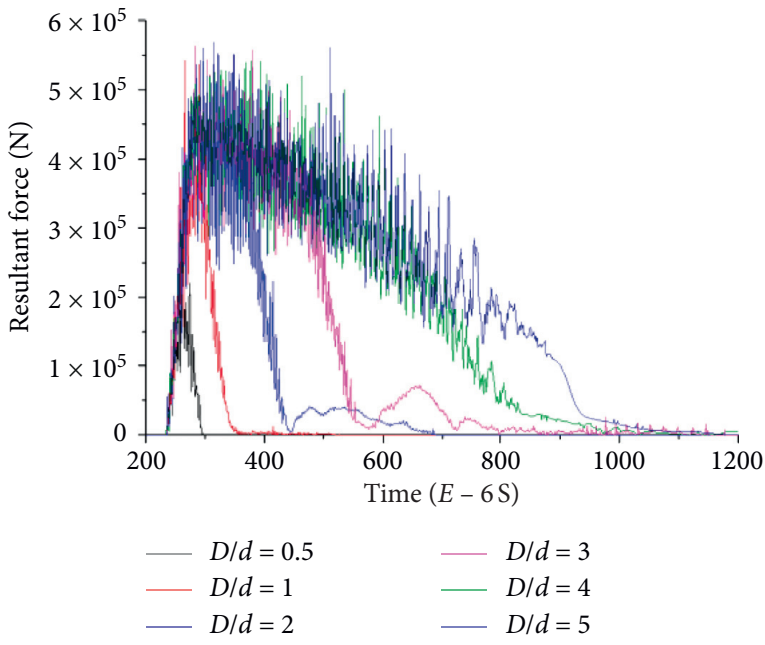

(a)

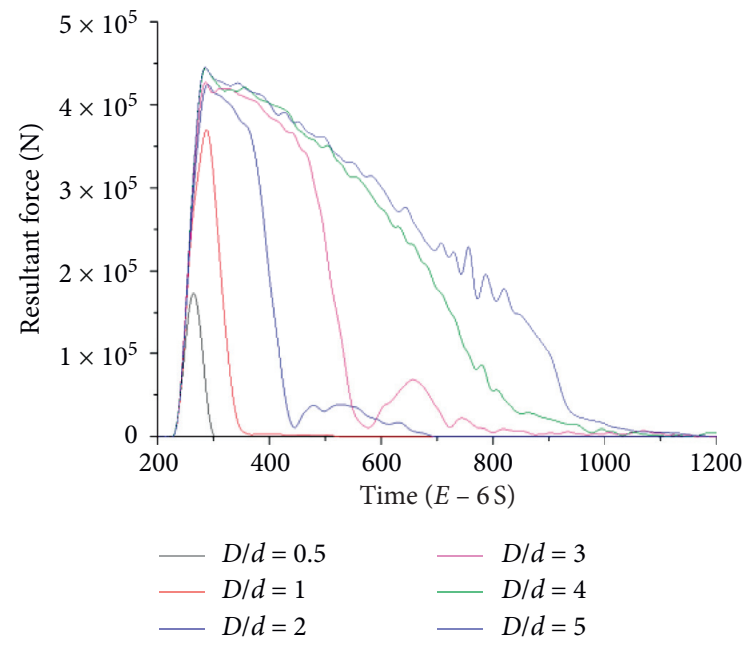

(b)

Figure 8: Contact force-time curves of stones of different sizes. (a) Contact force-time curves of stones. (b) Polished contact force-time curves of stones.

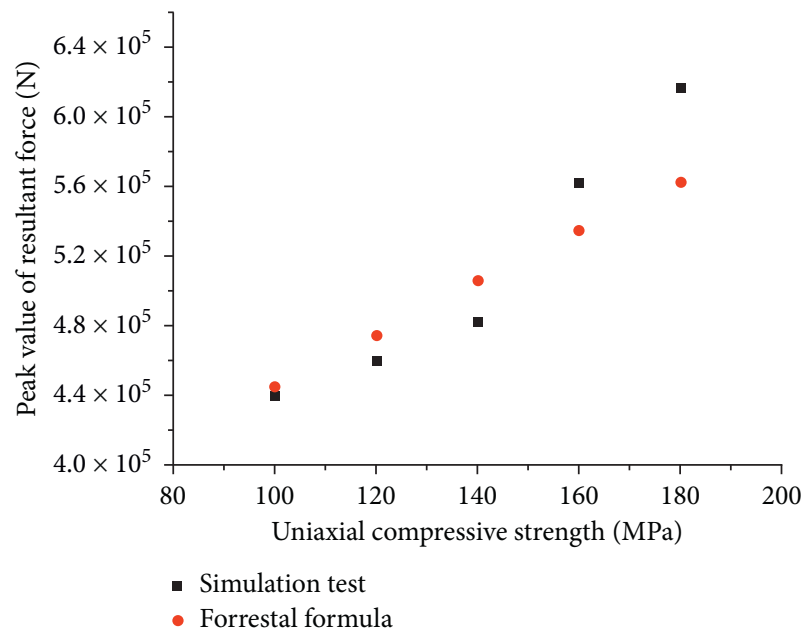

FIGURE 9: Peak value of resultant force between the simulation test and the Forrestal formula.

function of velocity and the normal stress of the warhead facets $\sigma_{r}$ can be expressed as

$$
\sigma_{r}=\frac{4}{3} \tau_{s}+\kappa \rho_{t} c_{p} v
$$

where $\tau_{s}$ is the shear strength of the target, $\kappa$ is related to the lateral pressure coefficient, $\rho_{t}$ is the density of the target, $c_{P}$ is the wave velocity of the target, and $v$ is the normal velocity of the facet. Based on CEB and RHT models and combined with experimental results, Gao [17] proposed that, within a certain strain rate range, the relationship between the compressive strength and strain rate of concrete meets the logarithmic relationship. Then, the static resistance term $R_{t}$ can be expressed in the following form:

$$
R_{t}=A_{0} \ln (v)+B_{0} \text {, }
$$

where $A_{0}$ and $B_{0}$ are the coefficients needed to be determined, which has to do with the strength of the target. Since stone and concrete are sensitive to the change of strain rate, considering the strain rate effect and the approximate linear relationship between strain rate and velocity, the expression of the normal stress of the warhead facets is modified as follows:

$$
\sigma=A\left(f_{c}\right)^{0.5}(\ln (v)-B)+\rho(v \cos \beta)^{2}, \quad v<1000 \mathrm{~m} / \mathrm{s},
$$

where $v(\mathrm{~m} / \mathrm{s})$ is the velocity of the projectile and $f_{c}(\mathrm{~Pa})$ is the uniaxial compressive strength of the target. The values of parameters $A$ and $B$ depend on the material of the target. Based on a large number of simulation experiments, $A=10423$ and $B=2.25$ are given for the concrete while $A=14325$ and $B=2.3$ are given for the stone.

\subsection{Discussion of the Modified Stress Model of Differential Facet}

3.3.1. Verification of the Stress Model of Concrete. In consideration of the influence of target strength and penetration velocity, the velocity of the projectile is set as $1000 \mathrm{~m} / \mathrm{s}$ and simulation tests are carried out on concrete targets with uniaxial compressive strength of $40,50,60,70$, and $80 \mathrm{MPa}$. Then, the strength of concrete is fixed at $48 \mathrm{MPa}$ based on the principle of the control variable method, and numerical experiments are carried out for the penetration velocity of $600,700,800,900$, and $1000 \mathrm{~m} / \mathrm{s}$, respectively. The modified differential facet model is used to solve the above penetration problems, and the comparison results with the simulation experiments are shown in Figure 11. It can be seen that the calculated resistance is close to the simulation results after taking the relationship between the static resistance term and the velocity into consideration.

3.3.2. Verification of the Stress Model of Stone. Simulation experiments are carried out on stone targets, of which the uniaxial compressive strength is set as 100, 120, 


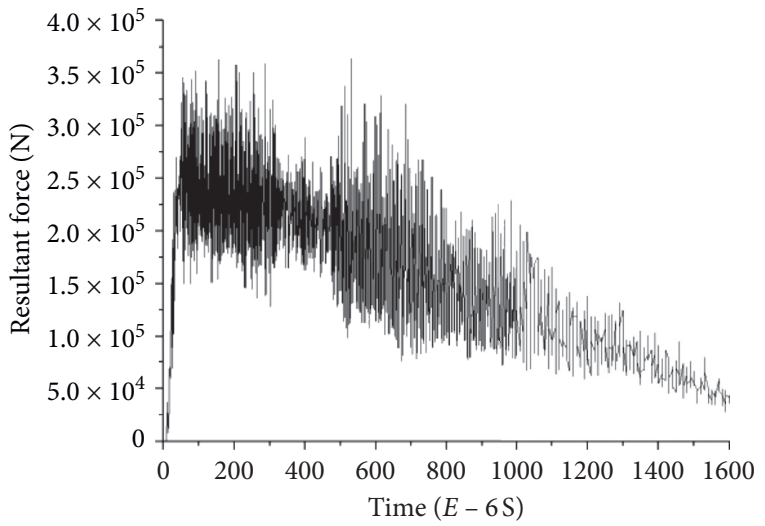

(a)

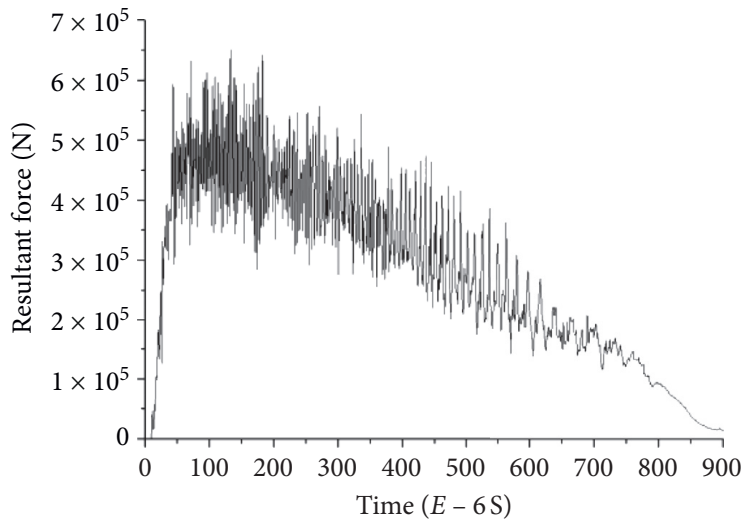

(b)

FIGURE 10: Contact force-time curves of penetrating concrete and stone at $1000 \mathrm{~m} / \mathrm{s}$. (a) Contact force-time curve of concrete penetration. (b) Contact force-time curve of stone penetration.
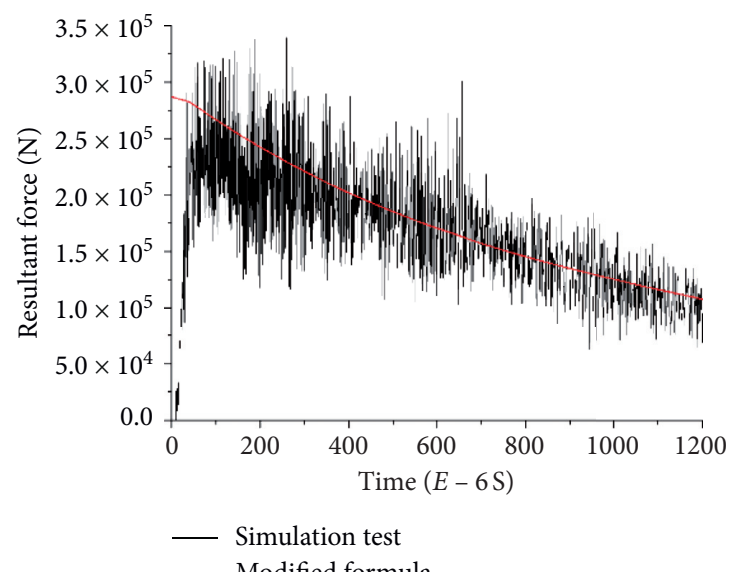

(a)

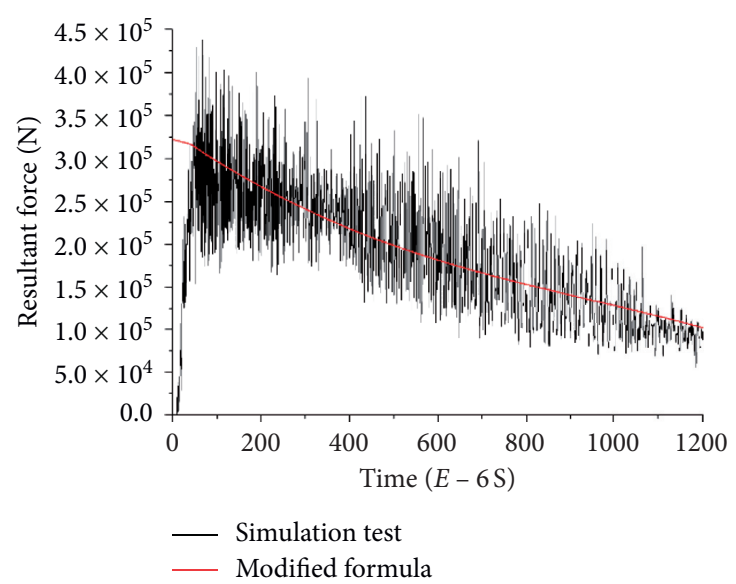

(c)

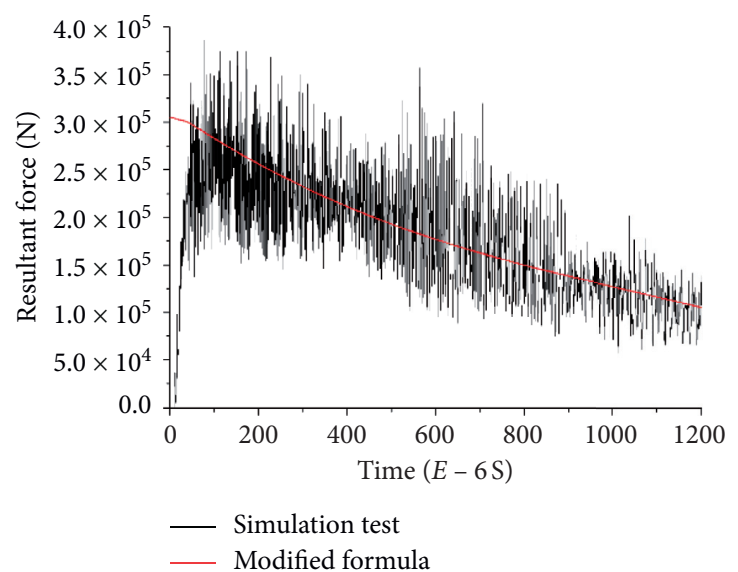

(b)

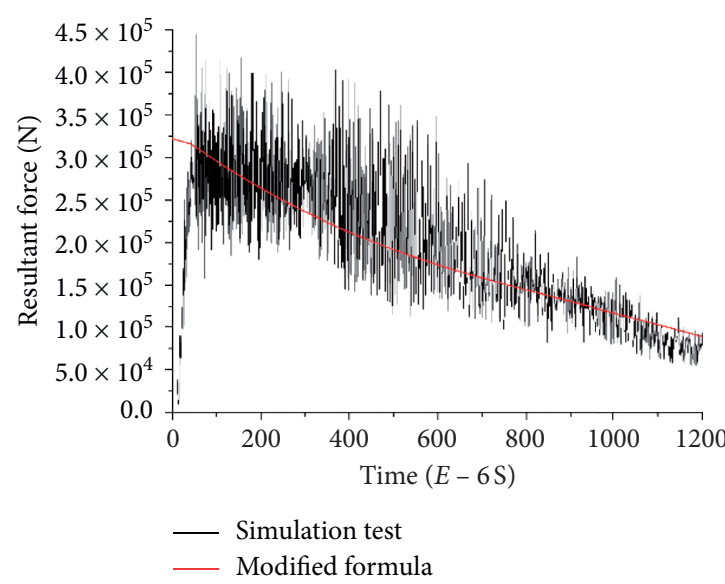

(d)

Figure 11: Continued. 


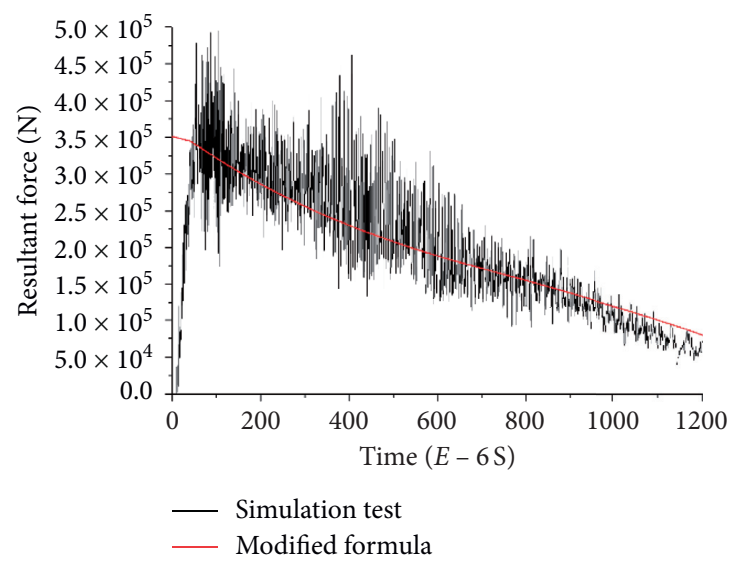

(e)

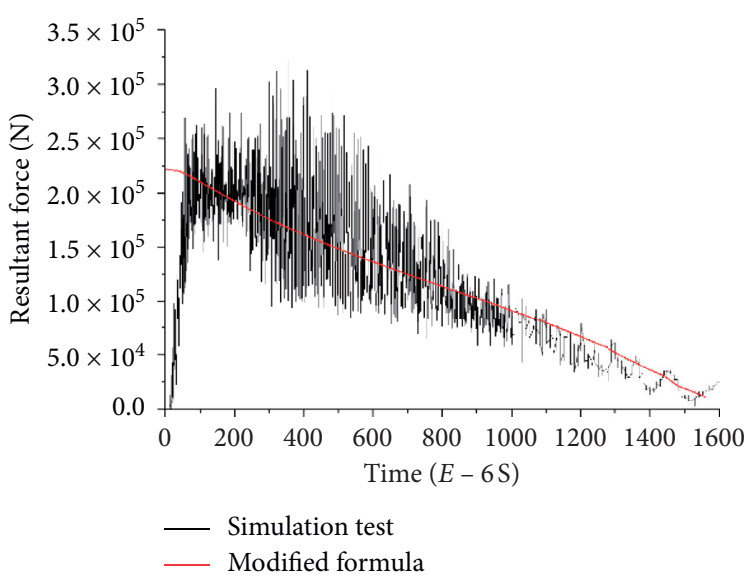

(g)

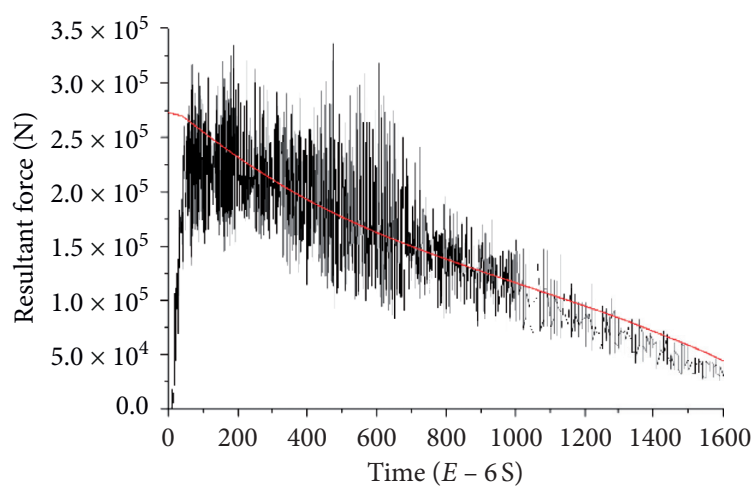

- Simulation test
- Modified formula

(i)

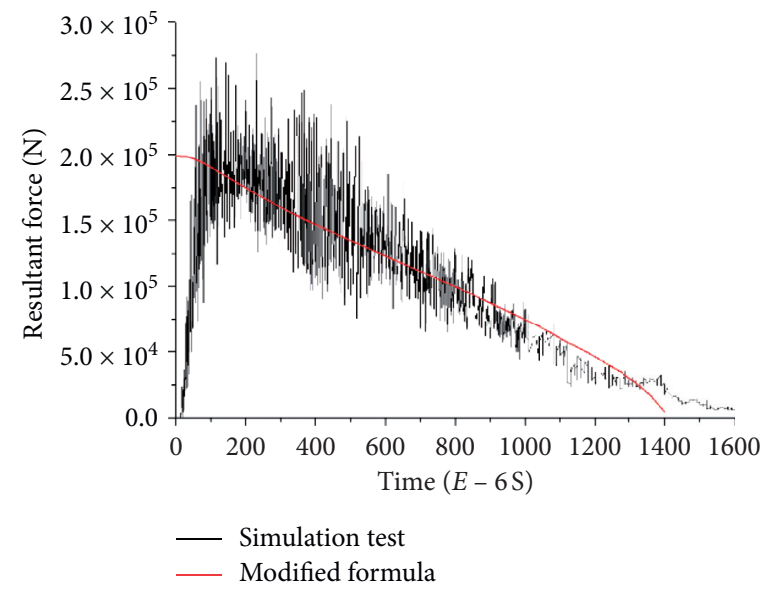

(f)

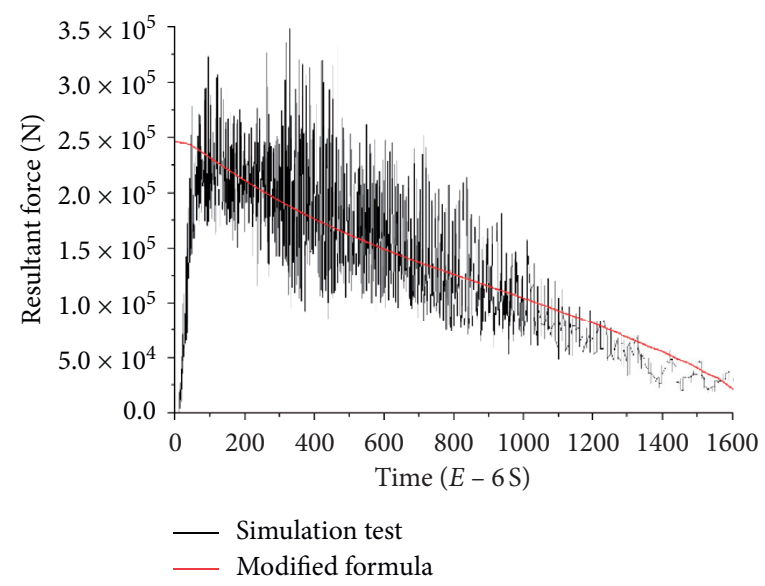

(h)

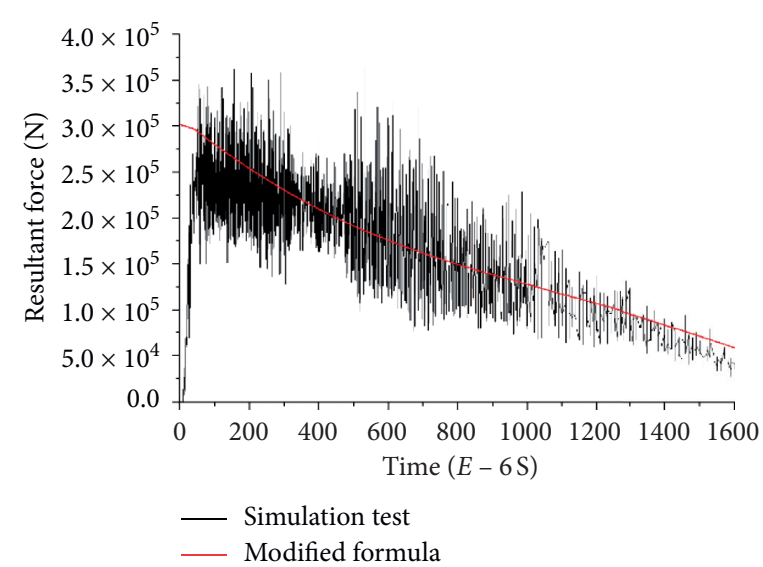

(j)

Figure 11: Comparison between simulation and modified formula of concrete penetration. (a) $40 \mathrm{MPa}$. (b) $50 \mathrm{MPa}$. (c) $60 \mathrm{MPa}$. (d) $70 \mathrm{MPa}$. (e) $80 \mathrm{MPa}$. (f) $600 \mathrm{~m} / \mathrm{s}$. (g) $700 \mathrm{~m} / \mathrm{s}$. (h) $800 \mathrm{~m} / \mathrm{s}$. (i) $900 \mathrm{~m} / \mathrm{s}$. (j) $1000 \mathrm{~m} / \mathrm{s}$.

140,160 , and $180 \mathrm{MPa}$, respectively. The penetration velocity of the projectile is $1000 \mathrm{~m} / \mathrm{s}$. Then, the penetration velocity is, respectively, set as $600,700,800,900$, and $1000 \mathrm{~m} / \mathrm{s}$, and the uniaxial compressive strength of stone target is fixed at $154 \mathrm{MPa}$. The modified differential panel stress model is used for solving the penetration problems, and comparison results with simulation tests are shown in Figure 12. It can be seen that the calculated resistance is close to that of simulation tests.

After the analytical expression of the axial stress of the differential facet is determined, the motion state of the projectile penetrating stone concrete can be further solved. 

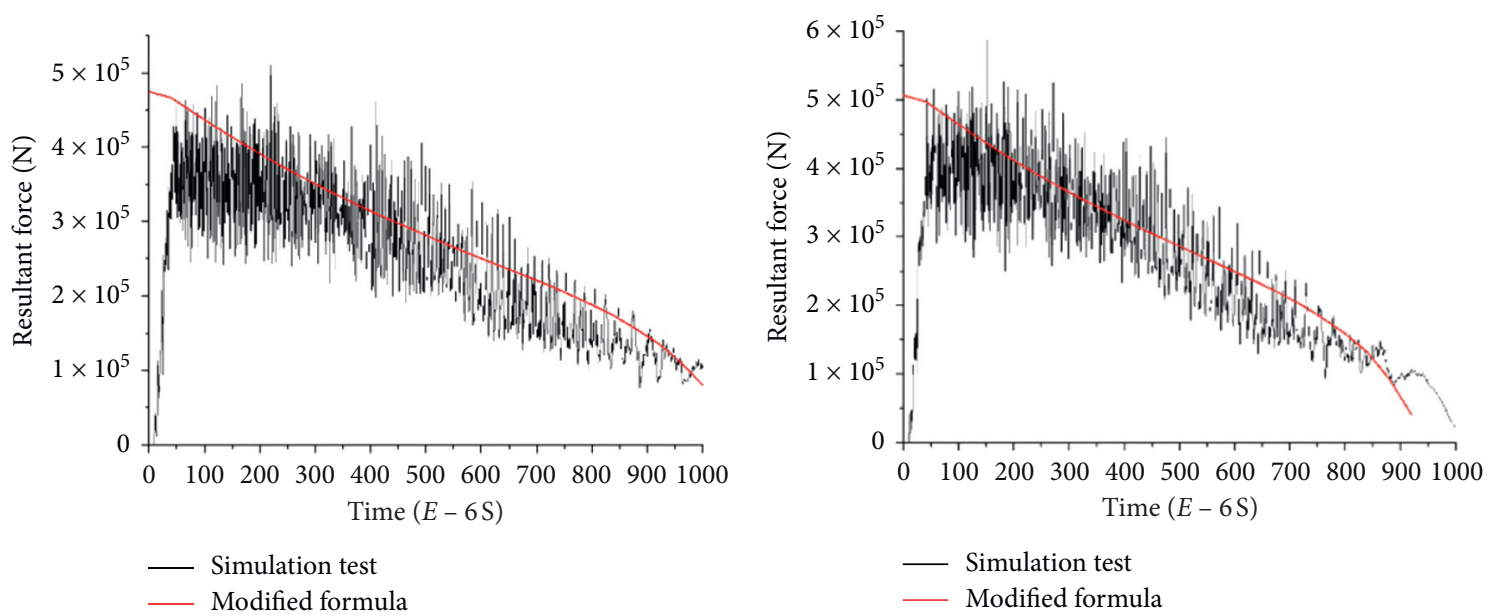

(a)
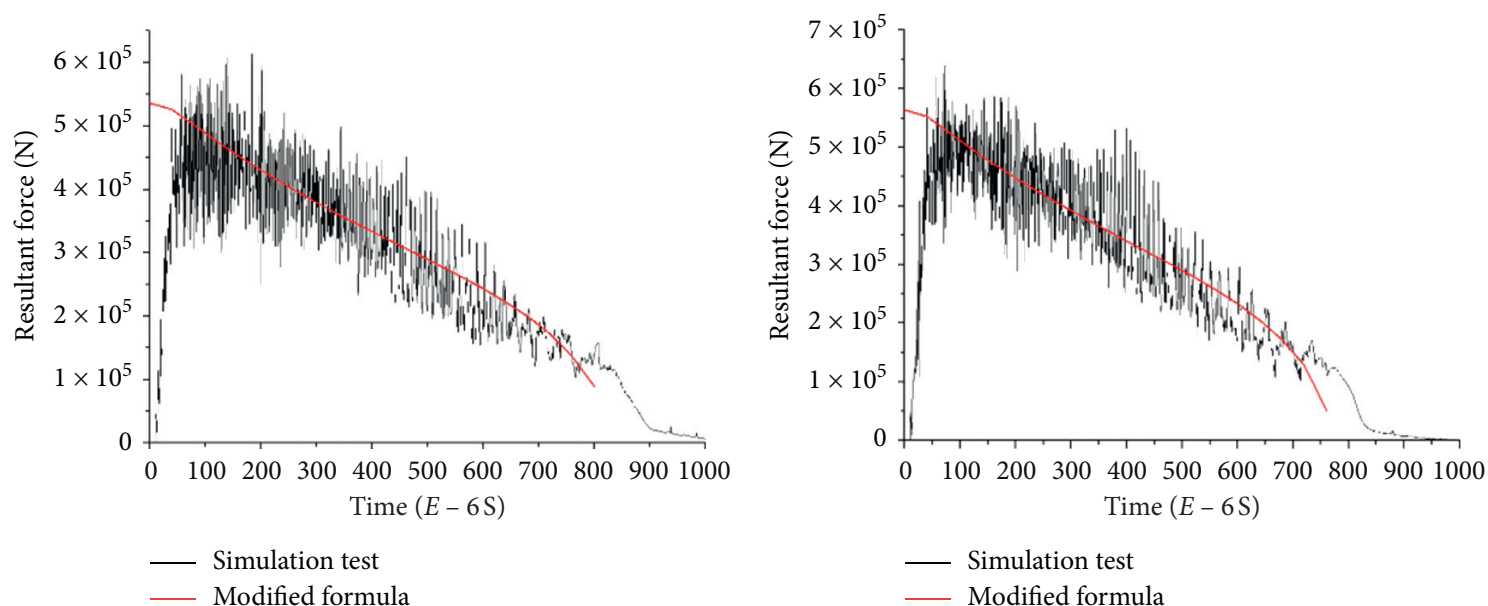

(c)

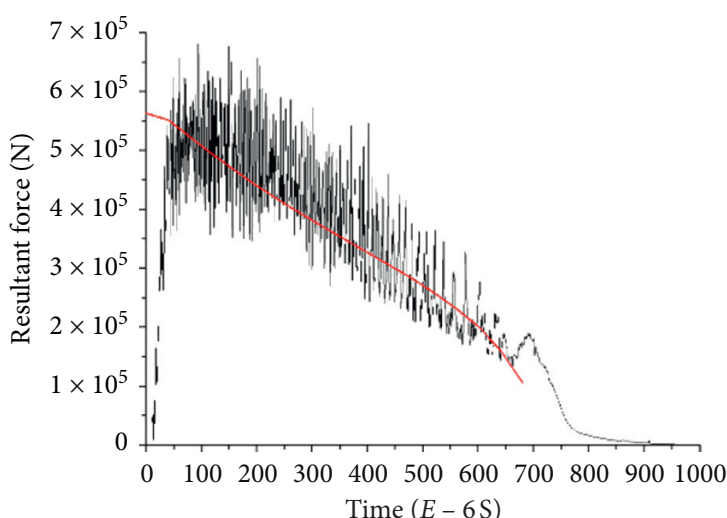

(d)

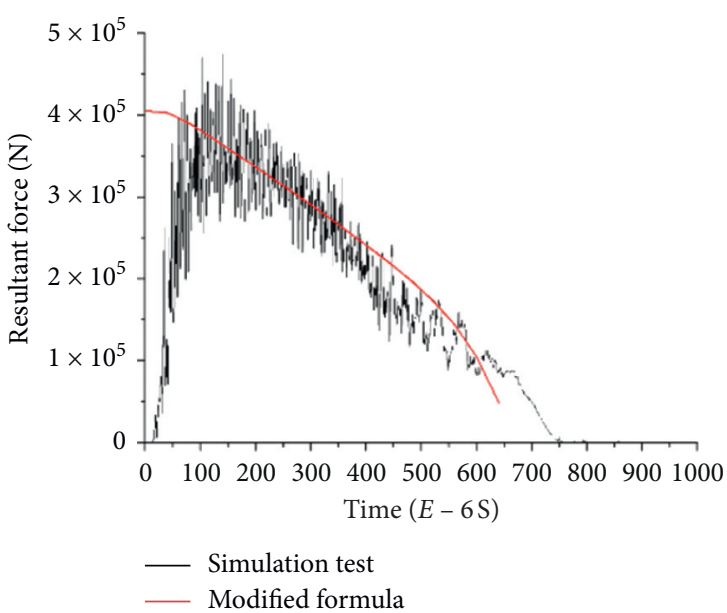

(e)

(f)

Figure 12: Continued. 


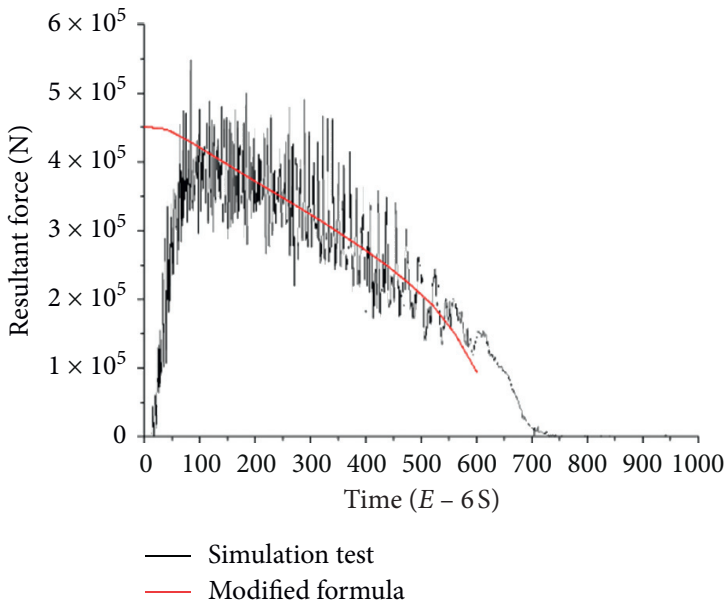

(g)

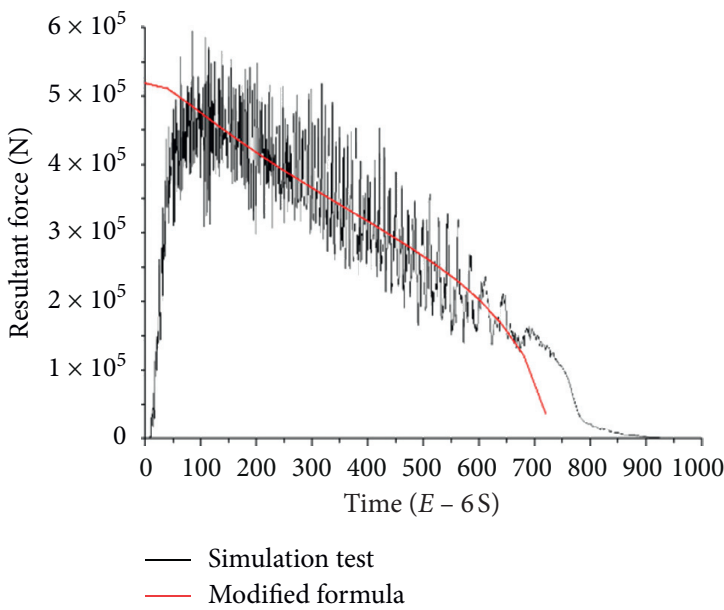

(i)

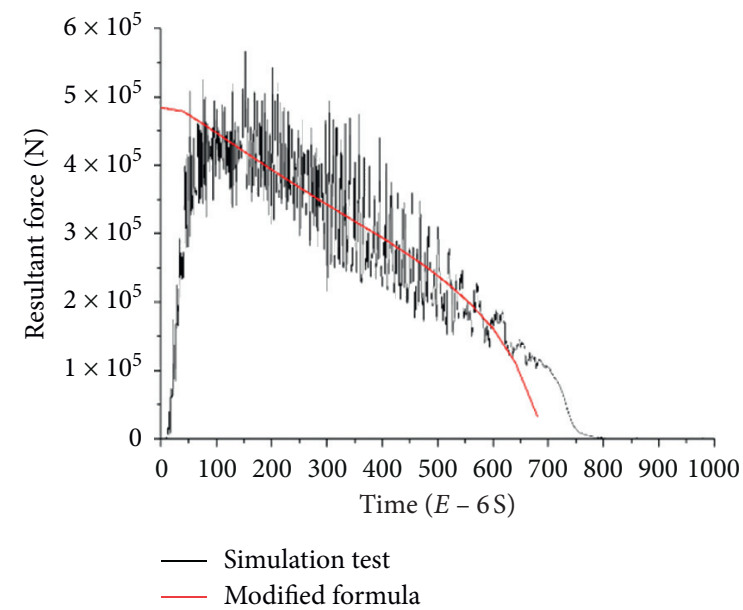

(h)

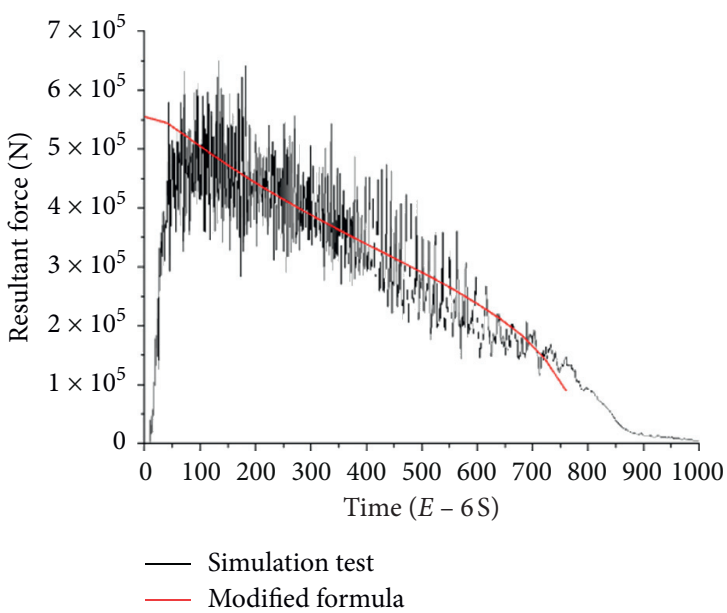

(j)

FIgURE 12: Comparison between simulation and modified formula of stone penetration. (a) $100 \mathrm{MPa}$. (b) $120 \mathrm{MPa}$. (c) $140 \mathrm{MPa}$. (d) $160 \mathrm{MPa}$. (e) $180 \mathrm{MPa}$. (f) $600 \mathrm{~m} / \mathrm{s}$. (g) $700 \mathrm{~m} / \mathrm{s}$. (h) $800 \mathrm{~m} / \mathrm{s}$. (i) $900 \mathrm{~m} / \mathrm{s}$. (j) $1000 \mathrm{~m} / \mathrm{s}$.

First of all, determine whether the facet is affected by force and the type of the force. Then, calculate the magnitude of force with the modified formula depending on the target the facet contacts to. Finally, we get the resistance of penetration into stone concrete by integrating stress of all facets. It can be seen that the calculation results with the modified formula of differential facet are in good agreement with simulation results.

\subsubsection{A Method for Fast Calculation of Penetration into Stone} Concrete. As for solving the penetration problem of stone concrete, the basic method is to solve the projectile motion by using the analytical expression of stress on the facet of the projectile and combining with the rigid body motion equation. Compared with simulation software, the calculation efficiency is improved on the basis of ensuring the accuracy as far as possible. The significance of establishing the differential facet stress model is that a general approximate solution can be obtained without considering the influence of the shape of warhead and different stages of penetration. It can be realized programmatically as follows:
(1) Establish the numerical model of stone concrete according to characteristics of the given target. After meshing, use the background grid method to determine the volume representing stones and concrete, respectively, by location.

(2) Divide the surface of the projectile into differential facets that match the target grid and then give a sufficiently small step. The time when the projectile body contacts the target is defined as the initial time, and the initial velocity of the projectile is defined as $v_{0}$.

(3) Stress on each facet is analyzed and calculated after a time step by position, and the stress is integrated to obtain the force state of the projectile. Then, the final speed and motion posture of the projectile in this forced state lasts for a time step is solved.

(4) Repeat step (3) until the specified time and the penetration trajectory of projectile in stone concrete can get solved.

In order to further verify the calculation results of the model, experiments of penetrating C35 concrete carried out 
TABLE 3: Comparison between tests and modified formula of penetration depth.

\begin{tabular}{lcc}
\hline \multirow{2}{*}{ Penetration velocity $(\mathrm{m} / \mathrm{s})$} & \multicolumn{2}{c}{ Penetration depth $(\mathrm{cm})$} \\
& Tests & Calculation \\
\hline 1000 & 79.5 & 81.24 \\
982 & 98.5 & 79.17 \\
873 & 63.0 & 67.93 \\
\hline
\end{tabular}

by Zhang et al. [18] are used for comparison. The parameters of the ogive nosed projectile are given as follows. The length $L=105 \mathrm{~mm}$, the diameter $D=15 \mathrm{~mm}$, and the mass $M=0.1 \mathrm{~kg}$. CRH of the projectile is 3 . The penetration depth is $63.0 \mathrm{~cm}$ when the penetration velocity is $873 \mathrm{~m} / \mathrm{s}$ and the penetration depth is $79.5 \mathrm{~cm}$ when the penetration velocity is $1000 \mathrm{~m} / \mathrm{s}$. The calculation results of the penetration depth are given by programming. Penetration is considered to stop when the velocity is less than $10 \mathrm{~m} / \mathrm{s}$.

It can be seen in Table 3 that the calculated results obtained by programming with the modified resistance formula are consistent with the experimental results. With the decrease of penetration velocity, the penetration depth decreases gradually. Through the comparison of the results, it can be seen that the accuracy of the model can meet the needs of practical engineering.

\section{Conclusion and Prospect}

In this paper, the factors influencing penetration problems of stone concrete are analyzed, such as the size and the strength of stones and the velocity of projectile. Some conclusions have been drawn:

(1) When the penetration velocity remains the same, increase of the resistance of penetrating stone becomes more and more obvious as the strength of the stone increases.

(2) Size of stone does not make an obvious effect on the magnitude of the facet stress of the projectile. And, when the relative size of stone is greater than 2 , the resistance of the projectile is close to that of penetrating the corresponding rock target.

(3) In the lower speed range, the static resistance term of the projectile in the penetration process should not be regarded as a constant. There is a logarithm relationship between the static resistance term and velocity, the coefficient of which is related to strength of the target.

The numerical model of stone concrete is established with the $3 \mathrm{D}$ Voronoi diagram and the analytical expression of differential facet stress is given according to the Forrestal and Rosenberg formula, based on which a fast algorithm is introduced to solve the penetration of stone concrete.

With the deepening of research, the upper limit of rigid projectile penetration velocity raises up to $1500 \mathrm{~m} / \mathrm{s}$, due to which the additional mass brought by high velocity needs to be considered. The application of high-performance composite fiber and new ceramics in the target makes viscosity effect of the target more and more obvious. In a higher velocity range, the projectile will deform obviously and the rigid projectile hypothesis cannot remain true. In the actual situation, the target cannot reach infinite size, so the overall structural response and local response will appear at the same time and interact with each other. There are also some limits in constructing heterogeneous targets based on Voronoi polyhedrons and a better construction method is worth exploring [19-21]. Taking the above into account, the differential facet stress model needs to be further developed and extended to penetration of different kinds of nonhomogeneous target.

\section{Data Availability}

The data used to support the findings of this study are included within the article.

\section{Conflicts of Interest}

The authors declare that they have no conflicts of interest.

\section{Acknowledgments}

This project was supported by the National Natural Science Foundation of China (no. 11972371).

\section{References}

[1] V. K. Luk and M. J. Forrestal, "Penetration into semi-infinite reinforced-concrete targets with spherical and ogival nose projectiles," International Journal of Impact Engineering, vol. 6, no. 4, pp. 291-301, 1987.

[2] M. J. Forrestal, D. J. Frew, S. J. Hanchak, and N. S. Brar, "Penetration of grout and concrete targets with ogive-nose steel projectiles," International Journal of Impact Engineering, vol. 18, no. 5, pp. 465-476, 1996.

[3] M. Q. Li and X. W. Chen, "Dimensionless formulae for penetration depth of concrete target impacted by a non-deformable projectile," International Journal of Impact Engineering, vol. 28, 2003.

[4] Z. Rosenberg and E. Dekel, "On the deep penetration of deforming long rods," International Journal of Solids and Structures, vol. 47, pp. 238-250, 2010.

[5] M. Y. Wang, J. Li, H. B. Li, and Y. Qiu, "Dynamic compression behavior of rock and simulation of damage effects of hypervelocity kinetic energy bomb," Explosion and Shock Waves, vol. 38, no. 6, pp. 23-40, 2018.

[6] Z. M. Wang, A. K. H. Kwan, and H. C. Chan, "Mesoscopic study of concrete I: generation of random aggregate structure and finite element mesh," Computers \& Structures, vol. 70, no. 5, pp. 533-544, 1999.

[7] X. F. Wang, M. Z. Zhang, and A. P. Jivkov, "Computational technology for analysis of 3D meso-structure effects on damage and failure of concrete," International Journal of Solids and Structures, vol. 80, pp. 310-333, 2016.

[8] Y. J. Deng, X. W. Chen, Y. Yao, and T. Yang, "On ballistic trajectory of rigid projectile normal penetration based on a mesoscopic concrete," Explosion and Shock Waves, vol. 37, no. 3, pp. 377-386, 2017.

[9] H. Langheim, H. Pahl, E. Schmolinske, and A. J. Stilp, "Subscale penetration tests with bombs and advanced penetration against hardened structures," in Proceedings of the 6th 
International Symposium on Interaction of Nonnuclear with Structures, pp. 12-17, Panama City Beach, FL, USA, May 1993.

[10] H. Guo, L. L. He, X. W. Chen, G. Chen, and J. Li, "Penetration mechanism of a high-speed projectile into a shelter made of spherical aggregates," Explosion and Shock Waves, vol. 40, no. 10, Article ID 103301, 2020.

[11] S. J. Hanchak, M. J. Forrestal, E. R. Young, and J. Q. Ehrgott, "Perforation of concrete slabs with $48 \mathrm{MPa}$ (ksi) and $140 \mathrm{MPa}$ (ksi) unconfined compressive strengths," International Journal of Impact Engineering, vol. 12, no. 1, pp. 1-7, 1992.

[12] L. J. Malvar, J. E. Crawford, J. W. Wesevich et al., "A plastic concrete material model for DYNA3D," International Journal of Impact Engineering, vol. 19, no. 9/10, pp. 847-873, 1997.

[13] C. C. Bi, Calibration of HJC Constitutive Parameters of Huashan Granite and its Blasting Damage Numerical Simulation, Hefei University of Technology, Hefei City, China, 2018.

[14] R. S. Bernard and D. C. Creighton, "Projectile penetration in soil and rock: analysis for non-normal impact," Technical Report SL-79-115AD-A081044, U. S. Army Waterways Experimental Station, Vicksbury, MS, USA, 1979.

[15] Y. H. Cheng, M. Y. Wang, D. R. Wang, C. Song, S. Yue, and Y. Tan, "Discussion on essences of static resistance of to types of material under penetration," Explosion and Shock Waves, vol. 40, no. 6, pp. 1-11, 2020.

[16] J. B. Xu, Investigations on Long Projectiles Penetrating into Concrete Targets, National University of Defense Technology, Changsha, China, 2001.

[17] G. F. Gao, "Influence and revision of transverse inertia effect and pressure hardening effect on strain-rate hardening effect of compressive strength of concrete," Transactions of Beijing Institute of Technology, vol. 40, no. 2, pp. 135-142, 2020.

[18] X. Y. Zhang, H. J. Wu, J. Z. Li et al., "Comparative study of projectile penetrating into two kinds of concrete targets at high velocity," Acta Armamentarii, vol. 40, no. 2, pp. 55-62, 2019.

[19] J. T. Fan, J. Weerheijm, and L. J. Sluys, "Compressive response of a glass-polymer system at various strain rates," Mechanics of Materials, vol. 95, pp. 49-59, 2016.

[20] Y. Liu, F. P. Vandermeer, L. J. Sluys, and J. T. Fan, “A numerical homogenization scheme used for derivation of a homogenized viscoelastic-viscoplastic model for the transverse response of fiber-reinforced polymer composites," Composite Structures, vol. 252, 2020.

[21] J. T. Fan, J. Weerheijm, and L. J. Sluys, "Compressive response of multiple-particles-polymer systems at various strain rates," Polymer, vol. 91, pp. 62-73, 2016. 